2014

San Diego, California, USA

\title{
An Effective Methodology for Drop Test Analysis and Optimization of Aerospace Composite Structures
}

\author{
Pham Dinh Chi \\ Institute of High Performance Computing
}

\begin{abstract}
An effective modeling strategy for drop test analysis of composite structures is proposed which allows engineers to generate feasible designs of complex structures undergoing impact. Traditional drop test analysis of 3D structural structures requires careful and detailed modeling and simulation, especially for composite materials where structural response may significantly vary upon changing the composite material properties, layup stacking or ply orientations. To account for various structural configurations, an optimization scheme that is computationally efficient is highly desired for composite design and analysis. This work illustrates a robust modeling strategy for drop test design and optimization of general composite structures by combining an explicit impact analysis of a 2D structural profile and subsequently a quasistatic analysis of the relevant 3D structure. This novel methodology is validated and shows good correlation with experimental results.
\end{abstract}

\section{References}

Pham, D.C, Narayanaswamy, S., "An optimization tool for impact analysis of composite structures". Procedia Engineering, 2014; 75: 3-8.

Pham, D.C., Narayanaswamy, S., "An effective modeling strategy for drop test analysis of composite curved beam", 56th AIAA/ASCE/AHS/ASC Structures, Structural Dynamics, and Materials Conference.

Pham DC, Sun X. "Experimental and computational studies on progressive failure analysis of notched cross-ply CFRP composite". International Journal of Computational Materials Science and Engineering. 2012, 1(03):1250023.

Pham DC, Sun XS, Tan VB, Chen B, Tay TE. "Progressive failure analysis of scaled double-notched carbon/epoxy composite laminates". International Journal of Damage Mechanics. 2012; 21(8):115485. 